\title{
Drosophila presenilin Is Required for Neuronal Differentiation and Affects Notch Subcellular Localization and Signaling
}

\author{
Yiquan Guo, ${ }^{1}$ Izhar Livne-Bar, ${ }^{1}$ Lily Zhou, ${ }^{1}$ and Gabrielle L. Boulianne ${ }^{1,2}$ \\ ${ }^{1}$ Program in Developmental Biology, Hospital for Sick Children, Toronto, Ontario, Canada M5G 1X8, and ${ }^{2}$ Department of \\ Medical Genetics and Zoology, University of Toronto, Toronto, Ontario, Canada
}

Presenilins are a highly conserved family of proteins first identified as causative genes in early onset familial Alzheimer's disease. Recent studies have suggested a role for presenilins in the Notch-signaling pathway, but their specific function within this pathway remains unclear. Here, we have characterized the Drosophila presenilin gene and protein and studied their interaction with Notch in both mutants and transgenics. We find that the Drosophila presenilin protein is proteolytically cleaved and broadly expressed during development with the highest levels in neurons within the larval CNS. We also show that mutations in Drosophila presenilin (Dps) genetically interact with Notch and result in an early pupal-lethal phenotype characterized by defects in eye and wing development and incomplete neuronal differentiation within the larval CNS. Moreover, we find that processing of Notch in the Golgi by the furin protease is unaffected in Dps mutants and that Notch is present and may even accumulate on the plasma membrane of neuroblasts in the larval CNS of Dps mutants. In contrast, overexpression of Dps in transgenics causes Notch to accumulate in the cytoplasm. Taken together, these results indicate that Drosophila presenilin is required for proper neuronal differentiation and may regulate the subcellular localization of Notch proteins within cells, necessary for their accumulation and subsequent signaling capabilities.

Key words: Drosophila; presenilin; Notch; localization; Delta; neurogenesis
Presenilins are a highly conserved, novel family of transmembrane proteins first identified as causative factors in familial Alzheimer's disease (Levy-Lahad et al., 1995; Rogaev et al., 1995; Sherrington et al., 1995). Recently, presenilins have also been implicated in cell-signaling events during development after the identification of a presenilin homolog sel-12 in Caenorhabditis elegans as a suppressor of an activated lin-12 mutation (Levitan and Greenwald, 1995). LIN-12 is a member of the Notch family of receptors that are thought to regulate cell fate decisions via local cell-cell interactions. This suggested that SEL-12/presenilins may be involved in regulating the activity of LIN-12/Notch. Further evidence of a role of presenilins in Notch signaling comes from the observation that presenilin 1 (PS1) knock-out mice demonstrate developmental abnormalities similar to those observed in Notch knock-out mice (Shen et al., 1997). The relationship between presenilin and Notch, however, remains unclear. In presenilin knock-out mice, the expression of Notch and Delta is severely downregulated, suggesting that presenilin plays a role in regulating the spatiotemporal expression pattern of Notch and Delta (Wong et al., 1997). However, it is unclear from these

\footnotetext{
Received April 30, 1999; revised June 15, 1999; accepted June 30, 1999.

Y.G. was supported by a Research Training Award from The Hospital for Sick Children and a fellowship from the Alzheimer's Society of Canada. This work was supported by grants to G.L.B. from the Medical Research Council of Canada, the Alzheimer's Association, and the American Health Assistance Foundation. We thank W. S. Trimble, E. Yeh, and S. E. Egan for useful discussions and critical review of this manuscript. We also thank P. Simpson, K. Blochlinger, K. Kaiser, and P. Deck for providing several of the fly lines used in this study. We especially thank Leo Pallank and Barry Ganetzky for providing us with EMS alleles and S. Artavanis-Tsakonas and K. Blochlinger for generously providing us with antibodies to Notch and Cut, respectively.

Y.G. and I.L.-B. contributed equally to this work.

Correspondence should be addressed to Dr. Gabrielle L. Boulianne, Program in Developmental Biology, Hospital for Sick Children, 555 University Avenue, Toronto, Ontario, Canada M5G 1X8.

Copyright (C) 1999 Society for Neuroscience $\quad 0270-6474 / 99 / 198435-08 \$ 05.00 / 0$
}

experiments whether the changes in Notch and Delta expression are primary events or the result of major developmental defects caused by lack of presenilin. An alternative model suggested that presenilins might interact with Notch by affecting its subcellular localization. This model was based on the initial observation that there was a specific reduction in the amount of green fluorescent protein-tagged LIN-12 fusion protein that accumulates on the apical membranes of vulval precursor cells in sel-12 loss-offunction mutations in C. elegans (Levitan and Greenwald, 1998). More recently, studies in mice and Drosophila have suggested that presenilin is required for processing of the Notch receptor required for the activation of downstream genes (De Strooper et al., 1999; Struhl and Greenwald, 1999; Ye et al., 1999). However, it remains unclear whether presenilin affects Notch processing directly or by affecting the trafficking of Notch or the protease required for this cleavage event.

To investigate the relationship between presenilin and Notch further, we have isolated and characterized mutations in the presenilin gene of Drosophila melanogaster. We find that loss-offunction mutations in Drosophila presenilin (Dps) are early pupal lethal with underdeveloped eye and wing imaginal disks and defects in neuronal differentiation. We also demonstrate that mutations in Dps genetically interact with Notch and Delta and show that Dps affects Notch subcellular localization. Specifically, we find that Notch is present and may even accumulate on the plasma membrane of neuroblasts in the larval CNS of loss-offunction $D p s$ mutants. In agreement with this observation, we find that Dps does not affect the initial processing of Notch that occurs within the Golgi to produce a functional receptor at the plasma membrane. Finally, we also find that Notch accumulates in cells from transgenic flies that overexpress Dps. Taken together these results show that presenilins are required for neuronal differentiation and may play a role in Notch-signaling events by affecting 
the subcellular distribution and subsequent signaling capability of Notch.

\section{MATERIALS AND METHODS}

Fly strains. The deficiencies $\operatorname{Df}(1) \mathrm{N}-8 / \mathrm{In}(1) \mathrm{dl}-49$, y1 Hw1 m2 g4, Dl[7]/ TM2, and Df(3L)ri-79c/TM3 and the Notch alleles $N^{\text {nd-3 }}$ and $N^{\text {Ax-1 }}$ were obtained from the Bloomington Stock Center. Dps mutants were generated by imprecise P-element excision as described (Pirrotta, 1986) and maintained in a yw mutant background over the balancers TM6, Ubx, and $\mathrm{y}+$ or $\mathrm{TM} 3, \mathrm{~Tb}$, and $\mathrm{Sb}$, allowing us to identify homozygous $D p s$ mutant larvae and pupae. Transgenic lines carrying a UAS-Dps transgene were generated by subcloning a full-length Dps cDNA into the polycloning site of the pUAST vector that contains a miniwhite+ reporter gene. The pannier-GAL4 line was obtained from the Bloomington Stock Center, and cut-GAL4 was obtained from K. Blochlinger. Heatshock-Dps lines were generated by subcloning a full-length $D p s$ cDNA into the polycloning site of the Casper vector. Transformants were generated using white ${ }^{1}$ recipients and standard P-transformation methodology (Spradling and Rubin, 1982). Rescue of Dps mutants was achieved by crossing an $h s-D p s$ transgene into a $D p s^{\mathrm{w} 6} / D p s^{46}$ background followed by a regimen of one $1 \mathrm{hr}$ heatshock per day for the entire life cycle of the fly.

Immunoblots and immunocytochemistry. Wild-type or mutant Dps protein in immunoblots was detected from extracts derived from second instar larvae, late third instar larvae, or early pupae and from transgenics carrying either a heatshock-Dps transgene or UAS-Dps expressed from a daughterless-GAL4 driver. Immunoblots and immunocytochemistry were performed using affinity-purified Dps-specific antibodies generated to an N-terminal peptide corresponding to amino acids $28-43$ of Dps or a C-terminal peptide corresponding to amino acids 520-538. Affinity purification of the antibody was performed using the ImmunoPure $\mathrm{Ag} / \mathrm{Ab}$ Immunobilization Kit (Pierce, Rockford, IL). Primary antibodies were detected with either HRP-conjugated (immunoblots) or fluorescein- or rhodamine-conjugated secondary antibodies (immunocytochemistry) (Jackson ImmunoResearch, West Grove, PA). Immunoblots to detect Notch protein were performed using the monoclonal antibody C17.9C6 (kindly provided by Dr. S. Artavanis-Tsakonas) that recognizes the intracellular domain of Notch (1:3000). To control for loading, we stained immunoblots with Ponceau S. Double-labeling of imaginal disks and CNS from wild type and Dps mutants was performed using rat ELAV antibody 7E8A10 (Developmental Studies Hybridoma Bank) and mouse CUT antibody (a gift from Dr. K. Blochlinger). The subcellular localization of Notch in Dps mutants was detected in the CNS of second or late third instar larvae by immunocytochemistry using the monoclonal antibody C17.9C6 to the intracellular domain of Notch (kindly provided by Dr. S. Artavanis-Tsakonas) (Fehon et al., 1990).

\section{RESULTS}

\section{Molecular organization of the Drosophila presenilin gene}

We and others have reported previously the cloning of the Drosophila presenilin gene and shown that it encodes a protein with over $50 \%$ amino acid identity to its vertebrate counterparts (Boulianne et al., 1997; Hong and Koo, 1997; Ye and Fortini, 1998). To facilitate the identification of mutations in Dps, we have isolated and characterized genomic clones encompassing the Dps locus. The Dps gene is entirely contained within $4 \mathrm{~kb}$ of genomic DNA and is flanked by the genes encoding lipoic acid synthase and the $50 \mathrm{~S}$ ribosomal protein L15. The Dps transcript is encoded by nine exons, eight of which comprise the coding sequence (Fig. 1). Overall, the structure of the Dps gene is highly related to both the vertebrate and C. elegans presenilins, and many of the intron-exon boundaries and splice sites are conserved. This is consistent with the idea that presenilin derives from a common ancestral gene. The Dps gene also gives rise to at least two distinct isoforms, dpsa1 and dpsa2, that result from differential splicing of exon 7. dpsa 2 differs from dpsa1 by an additional 14 amino acids that are located within the large hydrophilic loop between TM6 and TM7 (Boulianne et al., 1997; Ye and Fortini, 1998). This loop region is
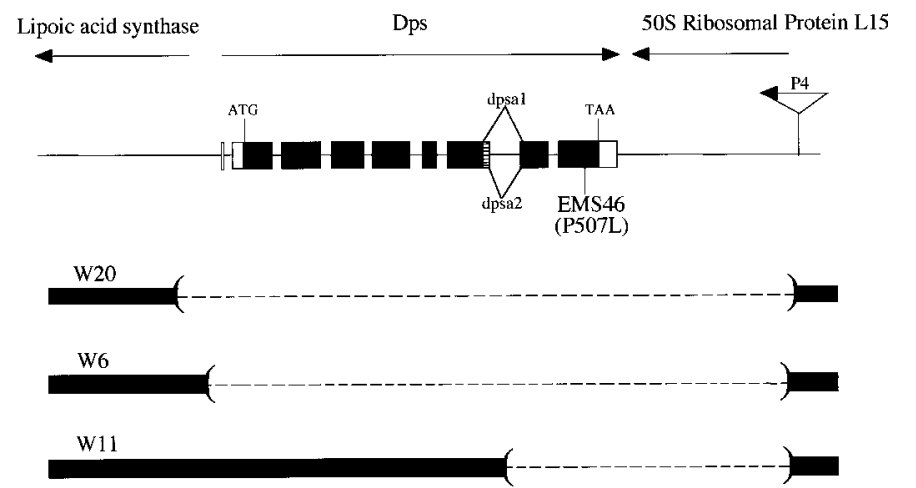

$\stackrel{0.5 \mathrm{~kb}}{\longmapsto}$

Figure 1. Genomic organization and deletion analysis of the Dps locus. The genomic organization of the $D p s$ gene was determined by sequencing genomic DNA obtained from a P1 clone (\#DS03069; Berkeley Drosophila Genome Project) and from genomic DNA obtained after plasmid rescue from the P4 insertion line (GenBank accession number, AF093402) as described (Pirrotta, 1986). The Dps gene is flanked on either side by the genes encoding lipoic acid synthase (accession numbers, AA820940 and AA201873) and $50 \mathrm{~S}$ ribosomal protein L15 (clone name, GM01846). Dps is comprised of nine exons (boxes) separated by eight introns. The location of an alternative splice site that gives rise to two dps (dpsa1 and dpsa2) isoforms is shown (hatched box). The P-element insertion P4 used to generate Dps deletions is shown. Overlapping deletions in Dps were generated by imprecise excision of the P-element $\mathrm{P} 4$ and are indicated by dashed lines. The $5^{\prime}$ and $3^{\prime}$ deletion break points were determined by a combination of Southern blot analysis using several restriction enzyme sites and sequencing of the break points from genomic DNA obtained from the deletion mutants, $W 20, W 6$, and $W 11$.

highly variable in both length and amino acid sequence between species, and it remains to be determined whether dpsa and dpsb are differentially expressed or have differential functions during development.

\section{Dps is proteolytically cleaved and broadly expressed during development}

To examine the processing as well as the cellular and subcellular distribution of Dps during development, we raised polyclonal antibodies to the $\mathrm{N}$ - and C-terminal domains of Dps. In agreement with previous Northern blot analyses (Boulianne et al., 1997), we find that Dps is ubiquitously expressed throughout development. The high levels of expression observed in $0-2 \mathrm{hr}$ embryos appear to result from large maternal contributions. In wild-type extracts the majority of endogenous Dps protein is proteolytically cleaved to an $\sim 25 \mathrm{kDa} \mathrm{N}$-terminal fragment (Fig. $2 a$ ) and an $\sim 35 \mathrm{kDa}$ C-terminal fragment (Fig. $2 b$ ). However, full-length Dps protein $(\sim 60 \mathrm{kDa})$ can be detected in transgenic flies that overexpress $D p s$ from a heatshock promoter or by the GAL4/UAS system (Brand and Perrimon, 1993) (Fig. 2c). The fact that presenilins are processed in worms, flies, and vertebrates suggests that the cellular machinery involved in this processing must be highly conserved between species. Using immunocytochemical techniques, we have found that Dps is widely distributed during development although some tissues, including the larval CNS, express higher levels of Dps. Within the CNS, Dps is mainly found in the axons and cell bodies of neurons and primarily within the cytoplasm (data not shown) (Ye and Fortini, 1998).

\section{Mutational analysis of Dps}

To examine the function of Dps, we generated a series of overlapping deletions by imprecise P-element excision of P4, a ho- 


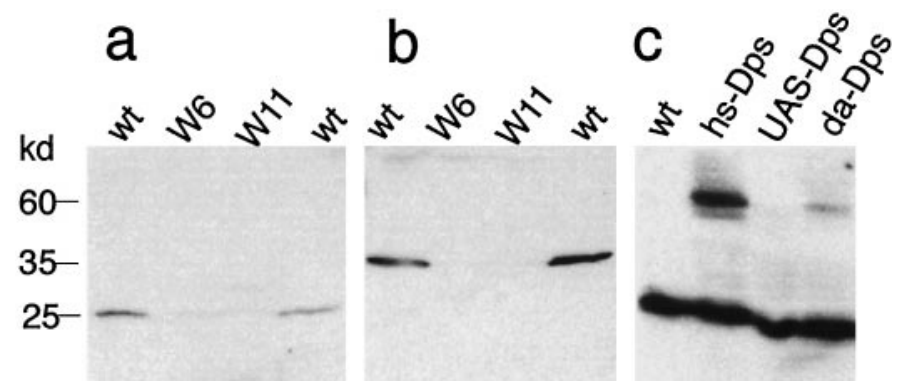

Figure 2. Dps is proteolytically cleaved. Immunoblot analysis of second instar larval extracts from wild type (wt) and mutants indicates that Dps is proteolytically cleaved to give rise to a $25 \mathrm{kDa}$-terminal fragment $(a)$ and a $35 \mathrm{kDa} \mathrm{C}$-terminal fragment $(b)$ that are absent from the deletion mutants W6 and W11. Full-length protein can only be detected in third instar larval extracts of transgenic flies that overexpress Dps from a heatshock promoter ( $h s-D p s)$ or use a daughterless-GAL4 driver (da-Dps) (c). In the absence of GAL4, only the N-terminal fragment is detected with the $\mathrm{N}$-terminal-specific Dps antibody.

mozygous viable P-element insertion located $\sim 1 \mathrm{~kb} 3^{\prime}$ of the Dps gene (Fig. 1). In total, we have generated six deletions, three of which remove portions of the Dps coding region $\left(D p s^{\text {W20 }}, D p s\right.$ w6, and $\left.D p s^{\mathrm{W} 11}\right)$. All of the deletions fail to complement each other, and none produce any detectable Dps protein as determined by Western blot analysis on extracts from mutant larvae (Fig. 2a,b). The largest deletion $\left(D p s^{\mathrm{W} 20}\right)$ deletes the $D p s$ gene as well as portions of the lipoic acid synthase and the $50 \mathrm{~S}$ ribosomal protein L15 genes and is embryonic lethal. $D p s^{\mathrm{W} 11}$ and $D p s^{\mathrm{W} 6}$ that delete Dps and the $50 \mathrm{~S}$ ribosomal protein L15 genes are lethal during the second larval instar, and these larvae are small and grow at a much slower rate.

In addition to the deletion mutants in Dps we have also characterized two EMS alleles, $D p s^{30}$ and $D p s^{46}$ (kindly provided by L. Pallank and B. Ganetzky), that were originally identified in a lethal screen over the deficiency $\mathrm{Df}(3 \mathrm{~L}) \mathrm{ri}-79 \mathrm{c} / \mathrm{TM} 3$ that uncovers the Dps locus and has break points at 77B-C;77F-78A. Both EMS lines fail to complement each other as well as the two Dps deletions we tested, $D p s^{\text {W6 }}$ and $D p s^{\text {W11. }}{ }^{\text {. To determine the mo- }}$ lecular basis of these mutations, we sequenced both $D p s^{30}$ and $D p s^{46}$. To date, we have been unable to identify a mutation within the coding region of $D p s^{30}$ and are currently searching for alterations in surrounding regulatory sequences. However, we have found a single missense mutation in $\mathrm{Dps}^{46}$, consisting of a proline to leucine substitution at amino acid 507 within the highly conserved C-terminal domain of Dps.

To address the function of Dps during development, we examined the phenotype in flies of the genotype $D p s^{46} / D p s^{\mathrm{W} 6}$ or $D p s^{46} / D p s^{\text {W11 }}$ that are mutant for $D p s$ but wild-type for lipoic acid synthase and hemizygous for the $50 \mathrm{~S}$ ribosomal protein L15 gene. We find that these mutants are early pupal lethal; the third instar larvae form a pupal case, but no adult structures develop. When we examined the phenotype of the mutants during the late third larval instar stage, we found that the mutant larvae have underdeveloped eye (Fig. 3b,e) and wing (Fig. 3c,f) imaginal disks. Although the eye imaginal disk forms, it fails to undergo proper neuronal differentiation (Fig. 3a,d). The wing imaginal disk is also smaller with the most severe defects observed in the region that will give rise to the wing blade (Fig. $3 f$ ). Furthermore, Wingless expression, which is normally detected in two domains within the developing disk, is disrupted in Dps mutant disks (Fig. $3 c, f)$. In contrast, both the antennae and leg imaginal disks
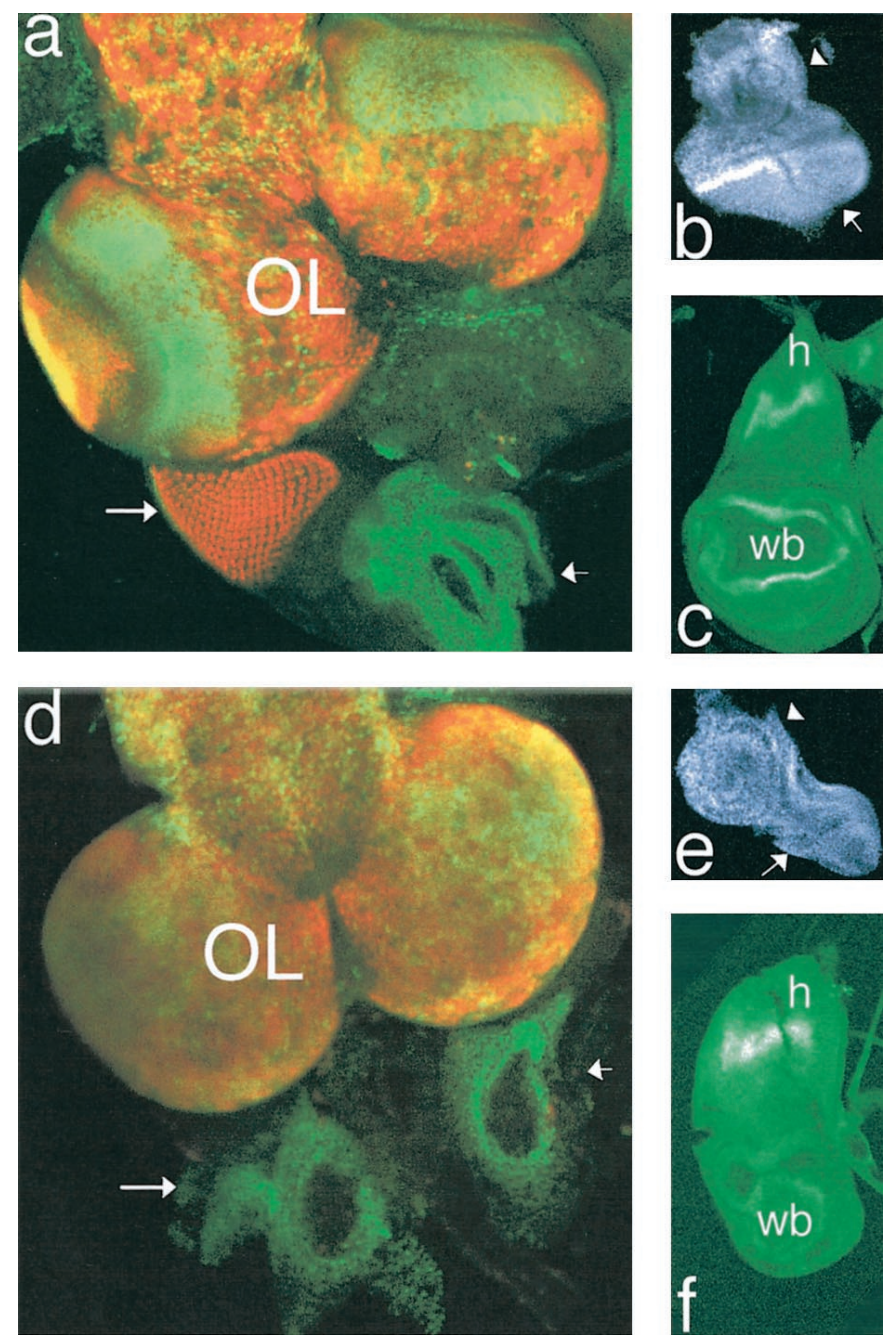

Figure 3. Dps mutants fail to undergo proper neuronal differentiation within the optic lobe anlagen and the eye imaginal disk. $a$, Wild-type CNS and disks derived from late third larval instar and double-immunostained for CUT (green) and ELAV (red). Note the precise laminar array organization of the optic lobe anlagen $(O L)$ and the regular array of neurons within the developing eye imaginal disk (long arrow). At this stage, CUT expression is also abundant in developing antennal disk (short arrow). $b$, DAPI staining of disks demonstrating the overall morphology of wildtype eye (arrow) and antennae (arrowhead) disks. $c$, Wild-type wing imaginal disks immunostained for WINGLESS. Note the normal distribution of wingless in the dorsal region of the wing disk in regions that will give rise to the adult notum and hinge $(h)$ and the ventral staining in regions of the wing blade $(w b)$ that will give rise to the wing margin. $d$, CNS and imaginal disks from $D p s^{46} / D p s^{\mathrm{W} 11}$ late third larval instar. Note the general disorganization of the optic lobe anlagen $(O L)$ and the absence of ELAV expression in the eye imaginal disk (long arrow). In contrast, expression of CUT in the antennal disk appears normal (short arrow). $e$, DAPI staining of disks from $D p s^{46} / D p s^{\mathrm{w} 11}$ mutants. Although the antennae disk (arrowhead) appears normal, the eye disk (arrow) is small and disorganized. $f$, Wing imaginal disks from $D p s^{46} / D p s^{\mathrm{W} 11}$. WINGLESS expression appears normal in the dorsal compartment in regions that will give rise to the notum and hinge $(h)$ but is absent from ventral regions that give rise to the wing blade and margin $(w b)$.

appeared normal. Both the lethality as well as the wing and eye phenotypes could be rescued using a $D p s$ transgene driven by a heatshock promoter. To determine whether there was any evidence of neuronal differentiation within the eyes and optic lobes of our pupal lethal mutants, we also examined the expression of two neuronal markers, ELAV (Robinow and White, 1988, 1991) 

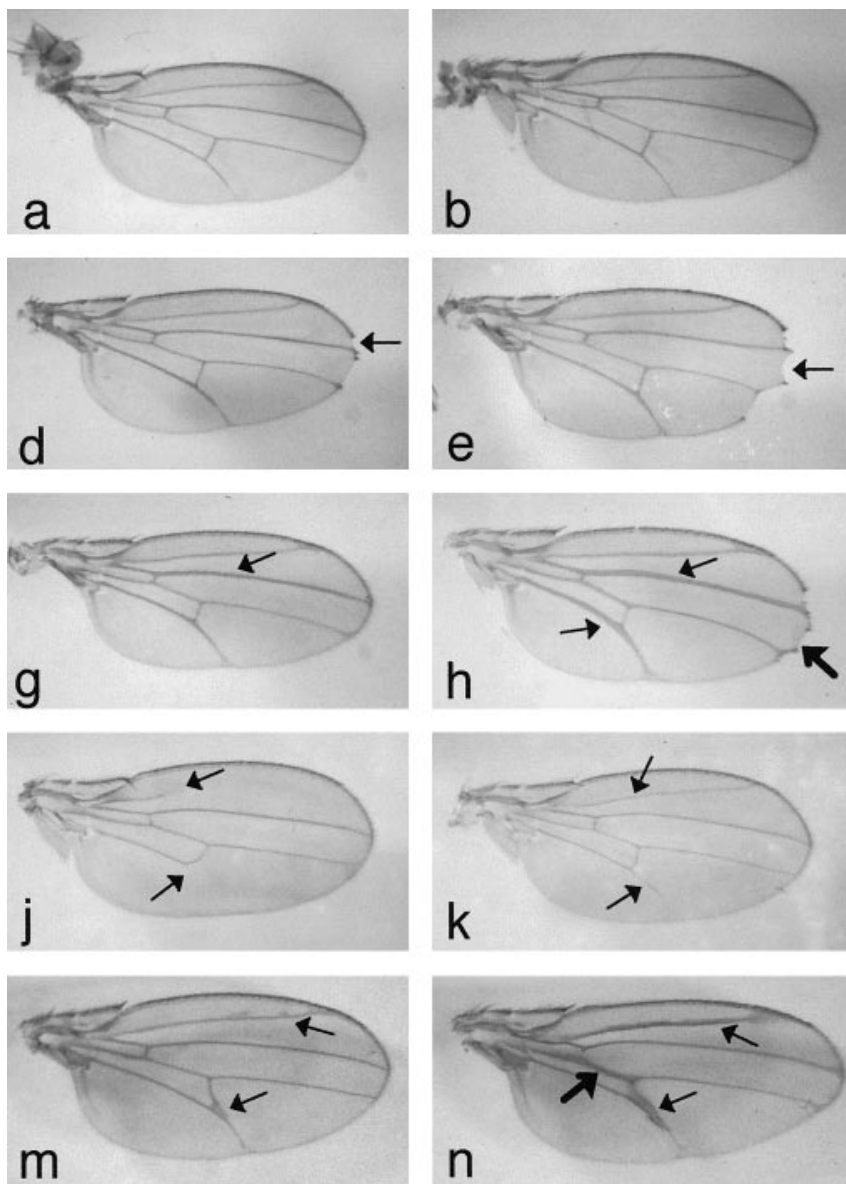
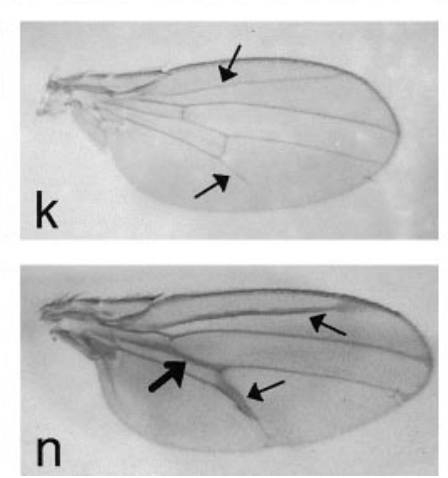
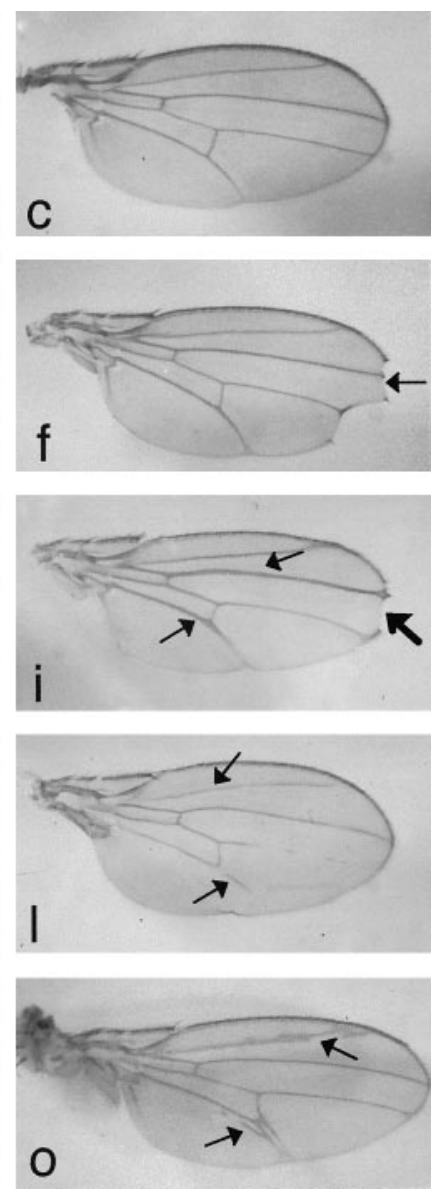

Figure 4. Dps genetically interacts with Notch and Delta. Dps mutants can modify the phenotype of both Notch and Delta alleles in transheterozygotes. $a$, Wild type. $b, D p s^{46} . c, D p s^{\text {w11 }} . d, D f(1) N-8$. Note the mild notching at the wing tip (arrow). $e, D f(1) N-8 ; D p s^{46}$. The $D p s$ mutations $(e, f)$ enhance the notching at the wing tip (arrow). $f, D f(1) N-8 ; D p s^{\text {w11 }} . g, N^{\text {nd-3 }}$. Note the thickening of wing vein L3 (arrow). $h, N^{\text {nd-3 }} ; D p s^{46}$. The $D p s$ mutations $(h, i)$ enhance the phenotype at the wing veins (thin arrows) and cause notching at the wing tips (thick arrow). $i, N^{\text {nd-3 }} ; D p s^{\text {W11 }} . j, N^{\text {Ax-1 }}$. Note the interruption of wing vein L5 and the absence of L2 (arrows). $k, N^{\mathrm{Ax}-1} ; D p s^{46}$. Note that the Dps mutation suppresses partially the interruption of L5 and restores L2 (arrows). $\left.l, N^{\mathrm{Ax}-1} ; D p s^{\mathrm{W} 11} . m, D l / 7\right]$. Note the thickening of the wing veins and the slight delta between L4 and L5 (arrows). $n, D l[7] ; D p s^{46}$. Dps mutants also enhance the wing vein phenotype of Delta mutants in transheterozygotes. Note the enhanced thickening of the wing veins and deltas (thin arrows, thick arrow). o, Dl[7]; Dps ${ }^{\mathrm{W} 11}$.

and CUT (Blochlinger et al., 1993), that are broadly expressed in neurons during postembryonic development. In wild-type eyeantennae imaginal disks of third larval instars, ELAV is expressed in photoreceptor neurons. CUT is absent from the eye disk at this stage but is broadly expressed in the antennae disk. At later stages, CUT can be detected in cone cells and sensory organ precursors that give rise to interommatidial bristles. We find that wild-type disks stain positively for ELAV (eye) and CUT (antennae), whereas mutant eye imaginal disks appeared small and underdeveloped and failed to express ELAV (Fig. 3a,b). Furthermore, although both CUT and ELAV could be detected in the developing optic lobes, the highly organized, laminar pattern of expression that is normally found in wild-type optic lobes failed to develop in Dps mutants. This suggests that Dps is required for eye and wing imaginal disk development, and although it is not required for the development of the optic lobes, they fail to differentiate properly without it.

\section{Dps genetically interacts with Notch and Delta}

A role for presenilins in the Notch-signaling pathway has been suggested previously by studies in both C. elegans (Levitan and Greenwald, 1995, 1998) and mice (Berezovska et al., 1997; Wong et al., 1997). To examine the link between Dps and Notch, we tested the ability of our Dps mutants to interact genetically with Notch (Fig. 4). Specifically, we crossed each Dps mutant to several alleles of Notch and determined whether any dosage-sensitive interactions could be detected in transheterozygotes. Such interactions have been shown previously for other known members of the Notch-signaling pathway. Initially we tested the ability of the point mutant $D p s^{46}$ and the deletions $D p s^{\mathrm{W} 6}, D p s^{\mathrm{W} 11}$, and $D p s^{\mathrm{W} 20}$ to interact with the deficiency $\operatorname{Df}(1) \mathrm{N}-8 / \operatorname{In}(1) \mathrm{dl}-49$, y1 Hw1 $\mathrm{m} 2 \mathrm{~g} 4$, that gives rise to dominant notching of the wing blade (Fig. $4 d$ ). We find that transheterozygotes containing one copy of the Notch deficiency and one copy of the $D p s^{46}$ mutation or a $D p s$ deletion all exhibited an enhanced wing phenotype (Fig. 4e,f). In addition, both $D p s$ alleles enhanced the phenotype of $N^{\text {nd-3 }}$, a loss-of-function allele of Notch that gives rise to a thickened wing vein phenotype at $29^{\circ} \mathrm{C}$ (Fig. $4 g$ ). Specifically, transheterozygotes between $N^{\text {nd-3 }}$ and Dps alleles have enhanced thickening of wing veins and notches at the tips of the wing similar to what is observed in stronger Notch alleles (Fig. 4h,i). This suggests that Dps mutations reduce Notch signaling within cells. In agreement with this, we found that Dps alleles suppressed the interrupted 

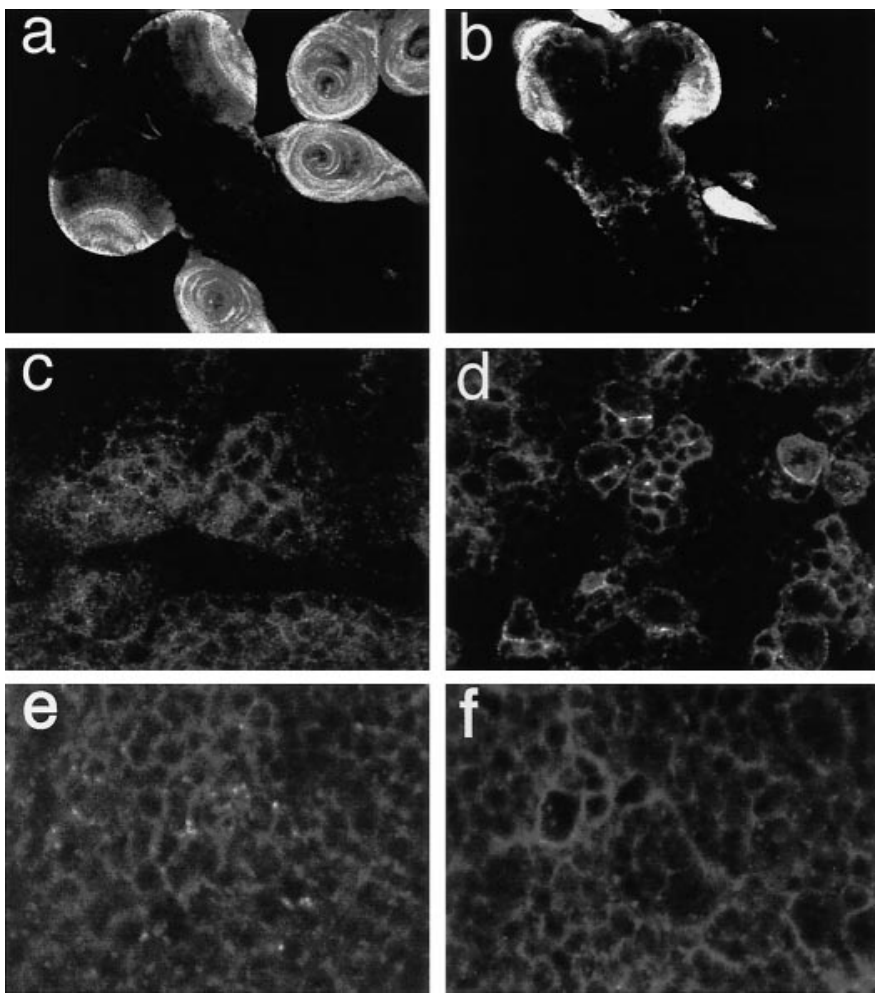

Figure 5. Notch staining is increased on the plasma membrane in the third larval instar CNS of Dps mutants. $a, c$, The distribution of Notch protein in the CNS of wild-type third instar larvae is shown at low $(a)$ and high $(c)$ magnification. Notch is expressed at high levels in the optic lobe anlagen and imaginal disks $(a)$. Within the CNS, Notch protein is detected within the cytoplasm and the plasma membrane $(c) . b, d$, In the CNS of Dps mutants, the overall pattern of Notch expression is affected $(b)$, and the protein levels are reduced in the cytoplasm and increased on the plasma membrane $(d) . e, f$, In contrast, the distribution of HRP on the plasma membrane is unaffected in Dps mutants. In wild type (e), HRP is found on the entire surface of neuroblasts in the CNS, and the same pattern of expression can be observed in Dps mutants $(f)$.

wing vein phenotype observed in the gain-of-function $N^{\mathrm{Ax}-1}$ allele (Fig. $4 j-l$ ). Finally, Dps mutants also enhanced the phenotype of the Delta allele Dl[7] that is characterized by thickened wing veins and small deltas located near cross-veins (Fig. 4m-o). Specifically, transheterozygotes between $\mathrm{Dl}[7]$ and Dps mutants exhibited a greater extent of thickening and deltas at the wing veins. Taken together, these results indicate that Dps mutations reduce Notch signaling and support a role for Dps in the Notchsignaling pathway.

\section{Dps affects the subcellular localization of Notch}

To gain insight into the mechanism underlying Dps and Notch interactions, we performed immunocytochemical studies to examine the subcellular distribution of Notch within the larval CNS of Dps mutants. Using an antibody that recognizes the Notch intracellular domain, we find that Notch is expressed at high levels within neuroblasts throughout the proliferative centers in the developing optic lobes and at somewhat lower levels in neuroblasts within the thoracic ganglia of third larval instar CNS as reported previously (Kidd et al., 1989; Fehon et al., 1991; Kooh et al., 1993). Within wild-type neuroblasts, Notch is distributed throughout the cytoplasm and on the plasma membrane (Fig. $5 a, c)$. In contrast, the overall distribution of Notch within the optic lobes is disrupted in Dps mutants, and the protein levels are
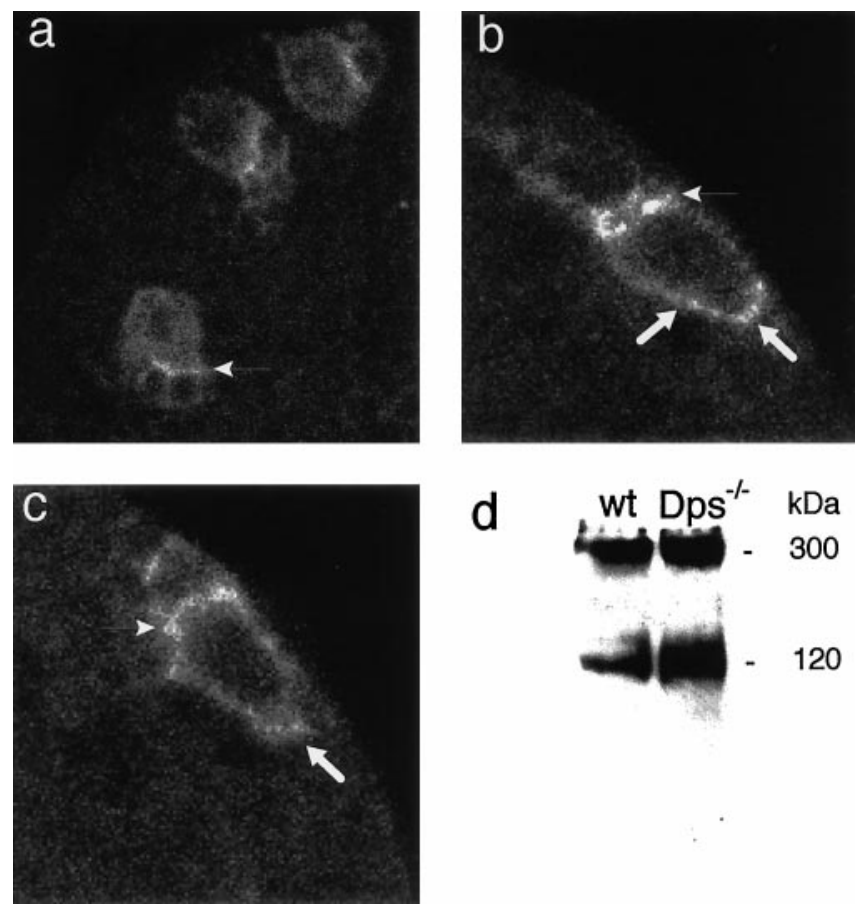

d

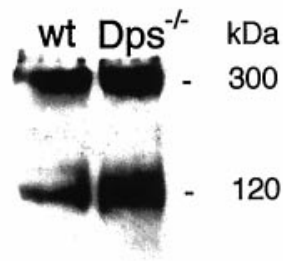

Figure 6. Notch staining is increased on the plasma membrane in the second larval instar CNS of Dps mutants. $a$, In wild-type second larval instar CNS, Notch expression is observed throughout the cytoplasm of neuroblasts and at high levels at the plasma membrane in regions of contact between the neuroblast and its progeny (arrow). b, $c$, In the CNS of Dps mutants, Notch expression is increased on the entire surface of the plasma membrane (thick arrows) and at the regions of contact between cells (thin arrow). $d$, Processing of Notch to give rise to a functional heterodimeric receptor is unaffected in Dps mutants. Protein extracts were obtained from isolated CNS and imaginal disks from wild-type and Dps homozygous mutant third larval instars. No significant differences were observed in the levels or processing of Notch in Dps mutants compared with that of wild type.

reduced in the cytoplasm and appear to be preferentially retained on the plasma membrane of specific neuroblasts (Fig. 5b,d). The affect on Notch subcellular localization appears to be specific because we observed no similar accumulation of HRP, a well characterized plasma membrane marker (Fig. 5e,f). Finally, to distinguish between primary effects of Dps on Notch localization versus secondary defects caused by altered differentiation of Dps mutants, we also examined the distribution of Notch protein within neuroblasts of second instar larvae. At this stage, Notch is expressed in small groups of cells that consist of a large neuroblast surrounded by smaller ganglia mother cells (Fig. 6a) (Fehon et al., 1991). Within these groups of cells Notch appears throughout the cytoplasm and at high levels at the plasma membrane in regions of contact between the neuroblast and its progeny. There is little, if any, accumulation of Notch at the plasma membrane in regions that contact the remaining surrounding cells. In contrast, we find that Notch distribution is altered with less in the cytoplasm and more staining seen over the entire plasma membrane of neuroblasts in Dps mutants (Fig. 6b,c). In agreement with this observation, we find that processing of Notch to give rise to a functional heterodimeric receptor on the cell surface is unaffected in Dps mutants (Fig. $6 d$ ).

We have also performed the reciprocal experiment to determine whether overexpression of Dps also affected the subcellular distribution of Notch. Specifically, we used the GAL4/UAS sys- 

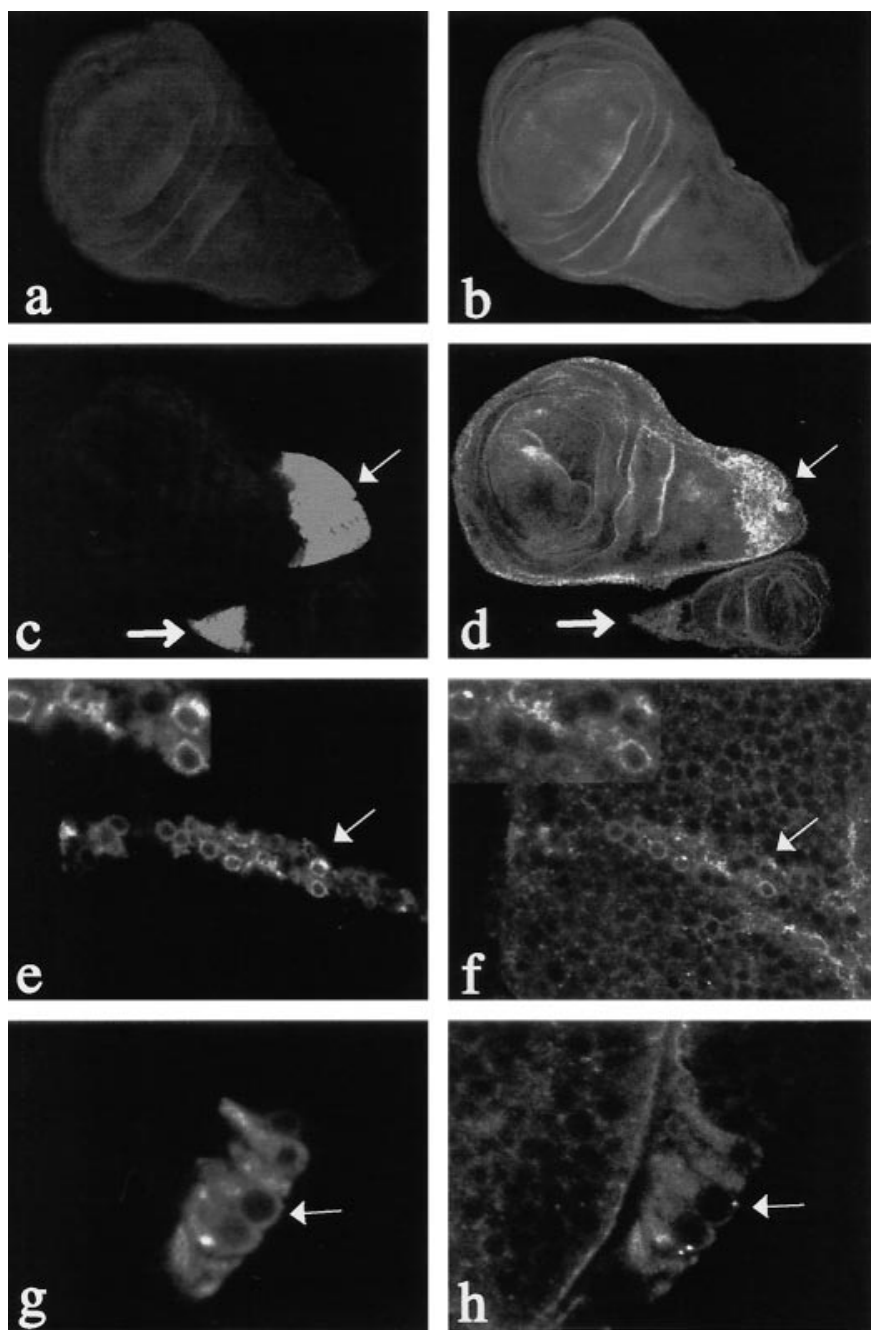

Figure 7. Notch staining is increased in the cytoplasm of Dpsoverexpressing cells. The distribution of Notch and Dps in third instar larval wing disks is shown. $a$, In wild-type disks, Dps protein is expressed at very low levels. $b$, Notch is expressed ubiquitously throughout the larval wing disk. $c, d$, Dps protein can be induced in wing (thin arrow) and haltere (thick arrow) disks using a pnr-GAL4 line to drive expression of UAS-Dps in transgenic lines $(c)$. Notch protein specifically accumulates in cells overexpressing Dps $(d)$. e, $f$, cut-GAL4 was used to overexpress $D p s$ at the developing wing margin. Note the high levels of Dps protein that accumulate in the cytoplasm of cells at the wing margin ( $e$, arrow). Overexpression of Dps at the margin causes Notch to accumulate within the cytoplasm of these cells ( $f$, arrow). $g, h$, Overexpression of Dps in a subset of neurons within the developing eye disk ( $g$, arrow) also causes increases in Notch expression within the cytoplasm of these cells ( $h$, arrow).

tem (Brand and Perrimon, 1993) to target expression of Dps to specific subsets of cells within a developing tissue. Specifically, we have used a pannier-GAL4 line (Fig. 7c,d) to drive expression of $U A S$-Dps in regions of the wing imaginal disk that will give rise to the adult notum and subsets of neurons within the eye imaginal disk or a cut-GAL4 line (Fig. 7e,f) that drives expression in the presumptive wing margin. We find that Notch protein specifically accumulates within Dps-expressing cells and appears to be primarily localized within the cytoplasm. In contrast, neighboring cells that do not overexpress Dps show no change in Notch expression or distribution. Similar results were obtained in singly stained preparations, confirming that none of the signals seen for
Notch were caused by bleed-through or secondary antibody crossreactivity (data not shown). In both cases, we found that Notch specifically accumulated in Dps-overexpressing cells but not in the adjacent cells (internal control) that only express basal levels of Dps (Fig. 7). Taken together, our results show Dps does not affect the ability of Notch to undergo furin-dependent cleavage within the Golgi and to accumulate on the plasma membrane. Rather, Dps may be affecting the subcellular distribution of Notch and later cleavage events leading to defects in cell signaling.

\section{DISCUSSION}

We have used Drosophila melanogaster to study the function of presenilin and to investigate its role in the Notch-signaling pathway. In Drosophila, presenilin is encoded by a single gene whose overall intron-exon structure and splice sites are highly related to that of both the C. elegans and vertebrate presenilins (Boulianne et al., 1997; Ye and Fortini, 1998). Although we and others (Boulianne et al., 1997; Ye and Fortini, 1998) have detected at least two distinct isoforms that arise from differential splicing, the significance of these two isoforms is presently unknown.

As found in its vertebrate and C. elegans counterparts, we find that the majority of Dps is proteolytically cleaved and gives rise to a $25 \mathrm{kDa} \mathrm{N}$-terminal fragment and a $35 \mathrm{kDa} \mathrm{C}$-terminal fragment, although full-length Dps can be detected in transgenic flies that overexpress Dps under a variety of promoters. The fact that presenilins are processed in worms, flies, and vertebrates suggests that this is a functionally important event and that the cellular machinery involved in this processing must be highly conserved between species. This is in contrast to previous studies in $C$. elegans that demonstrated that a naturally occurring mutation (PS1 $1 \mathrm{E} 9)$ that deletes exon 9 and removes the cleavage site is capable of rescuing a sel-12 mutant, thereby suggesting that proteolytic processing of presenilins was not essential for function (Levitan et al., 1996; Baumeister et al., 1997). More recently, however, several groups have demonstrated biochemical differences between the holoprotein and its proteolytic fragments (Walter et al., 1997; Steiner et al., 1998), and evidence has been obtained to suggest that Alzheimer mutations may act by impairing proteolytic processing of PS1 (Mercken et al., 1996). The major sites of proteolytic processing in vertebrate presenilins have been determined recently, and although processing of PS1 appears to generate a number of heterogenous products that map between $\mathrm{Thr}_{291}$ and $\mathrm{Ala}_{299}$, the majority of cleavage events occur between $\mathrm{Thr}_{291}$ and $\mathrm{Met}_{292}$ or $\mathrm{Met}_{298}$ and $\mathrm{Ala}_{299}$ (Podlisny et al., 1997). Interestingly, the amino acid sequence within this region is not conserved between flies, worms, and vertebrates, suggesting that the protease involved may recognize the overall structure of the protein rather than individual amino acid residues.

Using immunocytochemical techniques, we find that Dps is broadly expressed during development with higher levels in some tissues, including the larval CNS where the protein accumulates within the cytoplasm of neurons. This is consistent with a recent study showing that Dps is ubiquitously expressed throughout the cytoplasm during development with elevated levels in the larval and pupal optic lobes (Ye and Fortini, 1998). Interestingly, Dps mutants are early pupal lethal and have highly disorganized optic lobe anlagen. Although the optic lobes form, they do not appear to undergo proper neuronal differentiation as determined by the abnormal expression patterns of two neuronal markers, ELAV and CUT. Whether this reflects a primary defect caused by $D p s$ mutations or secondary effects that result from the absence of 
retinal innervation remains to be determined. Dps mutants also have small, undeveloped eye imaginal disks that do not express either marker even though other imaginal disks such as the ones that give rise to the legs or antennae develop normally. This suggests that Dps is required for the proper differentiation of a subset of neurons during development. It remains unclear why mutations in Dps affect only a subset of tissues during development because Dps is broadly expressed. The absence of an earlier phenotype may reflect, in part, high levels of maternal RNA and protein that is deposited into the embryo and may be sufficient for early embryonic development and the maturation of certain tissues. In agreement with this model, we observe very high levels of Dps RNA and protein in 0-3 hr embryos (data not shown), and others have shown recently that germ-line mutations in Dps are embryonic lethal and are characterized by a neural hyperplasia similar to that observed in Notch and Delta mutants (Struhl and Greenwald, 1999; Ye et al., 1999). Similarly, the fact that mutations primarily affect the optic lobes and eye imaginal disks may simply reflect a higher requirement for Dps in those tissues, and this is consistent with the observation that Dps is expressed at higher levels within these tissues (Ye and Fortini, 1998).

Dps mutations also enhance the wing phenotype of Notch and Delta loss-of-function mutants and suppress the phenotype of a Notch gain-of-function mutation, indicating that the signaling through the Notch receptor is reduced in Dps mutants and that the role of Dps in Notch signaling is not limited to the nervous system. More importantly, Notch is maintained and may even accumulate at the plasma membrane of neuroblasts in flies lacking Dps, whereas overexpression of Dps causes Notch to accumulate within the cytoplasm. Taken together, these data imply either that the cell surface Notch that we observe in Dps mutants is nonf unctional, unable to interact properly with its ligand, or that Dps blocks signal transduction events that occur at the membrane or after Notch is internalized from the membrane. Processing and trafficking of Notch receptors are known to be important for Notch signaling (Blaumueller et al., 1997; Pan and Rubin, 1997; Struhl and Adachi, 1998). Notch protein is synthesized in the endoplasmic reticulum and then undergoes an initial cleavage in the extracellular domain within the trans-Golgi network (Blaumueller et al., 1997). This initial cleavage step appears to be required to produce a functional heterodimeric Notch receptor at the cell surface because full-length Notch is only detected in the cytoplasm (Logeat et al., 1998). We note that this cleavage step is unaffected in Dps mutants and, consistent with this observation, that Notch protein is present at the plasma membrane, demonstrating that presenilin must act at a later step in Notch signaling. At the plasma membrane, Notch interacts with its ligands, triggering additional proteolytic cleavage steps that result in the release of the intracellular domain of Notch that then enters the nucleus and activates downstream genes (Schroeter et al., 1998; Struhl and Adachi, 1998). The Notch-Delta complex is also thought to be endocytosed, although the relationship between receptor endocytosis, cleavage, and nuclear transport is not yet clear (Seugnet et al., 1997). Recently, several studies have shown that presenilin mutants affect the proteolytic cleavage of Notch that gives rise to the intracellular domain, resulting in reduced signaling activity (De Strooper et al., 1999; Struhl and Greenwald, 1999; Ye et al., 1999). It is unclear, however, whether presenilin affects Notch cleavage directly or rather affects the trafficking of Notch or its protease within the cell. A recent study by Wolfe et al. (1999), in which two transmembrane aspartates in presenilin were mutated and shown to affect both endoproteolysis of prese- nilin and $\gamma$-secretase cleavage of amyloid precursor protein (APP), suggests that presenilin may have $\gamma$-secretase activity and directly cleave Notch. These studies, however, also do not distinguish between a direct role for presenilin in Notch cleavage versus a role in the trafficking of Notch or its protease.

In our studies, we find that Notch is uniformly distributed and may even accumulate on the entire plasma membrane of neuroblasts in Dps mutants. This is in contrast to wild-type situations in which Notch specifically accumulates at the interface of ligandexpressing cells during signaling both in cell culture and in vivo. Therefore, presenilin may be affecting targeting of Notch to the appropriate location on the membrane where it can interact with ligand. In the absence of ligand interaction, proteolytic processing of Notch does not occur. Alternatively, Dps could be required for internalization of the receptor-ligand complex and subsequent proteolytic processing because it is not known where within the cell these cleavage events occur. Although presenilin in mammals is thought to reside predominantly in the endoplasmic reticulum (ER) and Golgi, consistent with possible roles in early stages of protein processing, some evidence suggests that it may transiently reach the plasma membrane (Dewji and Singer, 1997) where it could participate in endocytic processes. In fact, in Drosophila, Dps has been shown to accumulate within vesicular structures throughout the cytoplasm, including the ER and Golgi, and is also found at the apical regions of cells in some tissues (Ye and Fortini, 1998).

A role for presenilin in protein processing or trafficking has been suggested previously on the basis of its subcellular localization (Kovacks et al., 1996; Walter et al., 1996; De Strooper et al., 1997) and its ability to affect the processing of APP in vertebrates (Borchelt et al., 1996; Duff et al., 1996; Scheuner et al., 1996). APP, like Notch, encodes a single-pass transmembrane protein found at the plasma membrane that is known to undergo several cleavage steps giving rise to two secreted peptides, $A \beta(40)$ and $\mathrm{A} \beta(42-43)$. Recent studies in transgenic mice have shown that presenilins can affect the processing of both Notch and APP by mechanisms that are unknown. Current models suggest that presenilins may directly cause cleavage of Notch and APP or, alternatively, affect the ability of secretases to cleave (De Strooper et al., 1998). Alternatively, presenilins may play a more general role in regulating the subcellular distribution of transmembrane proteins like APP and Notch within the cell, thereby physically altering their ability to interact with proteases necessary for their proper signaling functions.

\section{REFERENCES}

Baumeister R, Leimer U, Zweckbronner I, Jakubek C, Grunberg J, Haass C (1997) Human presenilin-1, but not familial Alzheimer's disease (FAD) mutants, facilitate Caenorhabditis elegans Notch signalling independently of proteolytic processing. Genes Funct 1:149-159.

Berezovska O, Xia M, Page K, Wasco W, Tanzi R, Hyman B (1997) Developmental regulation of presenilin mRNA expression parallels Notch expression. J Neuropathol Exp Neurol 56:40-44.

Blaumueller CM, Qi H, Zagouras P, Artavanis-Tsakonas S (1997) Intracellular cleavage of Notch leads to a heterodimeric receptor on the plasma membrane. Cell 90:281-291.

Blochlinger K, Jan LY, Jan YN (1993) Postembryonic patterns of expression of cut, a locus regulating sensory organ identity in Drosophila. Development 117:441-450.

Borchelt DR, Thinakaran G, Eckman CB, Lee MK, Davenport F, Ratovitsky T, Prada C-M, Kim G, Seekins S, Yager D, Slunt HH, Wang R, Seeger M, Levey AI, Gandy SE, Copeland NG, Jenkins NA, Price DL, Younkin SG, Sisodia SS (1996) Familial Alzheimer's disease-linked presenilin 1 variants elevate A $\beta 1-42 / 1-40$ ratio in vitro and in vivo. Neuron 17:1005-1013. 
Boulianne GL, Livne-Bar I, Humphreys JM, Liang Y, Lin C, Rogaev E, St George-Hyslop P (1997) Cloning and characterization of the Drosophila presenilin homologue. NeuroReport 8:1025-1029.

Brand AH, Perrimon N (1993) Targeted gene expression as a means of altering cell fates and generating dominant phenotypes. Development 118:401-415.

De Strooper B, Beullens M, Contreras B, Levesque L, Craessaerts K, Cordell B, Moechars D, Bollen M, Fraser P, St George Hyslop P, Van Leuven F (1997) Phosphorylation, subcellular localization, and membrane orientation of the Alzheimer's disease-associated presenilins. J Biol Chem 272:3590-3598.

De Strooper B, Saftig P, Craessaerts K, Vanderstichele H, Guhde G, Annaert W, Von Figura K, Leuven FV (1998) Deficiency of presenilin-1 inhibits the normal cleavage of amyloid precursor protein. Nature 391:387-390.

De Strooper B, Annaert W, Cupers P, Saftig P, Craessaerts K, Mumm JS, Schroeter EH, Schrijvers V, Wolfe MS, Ray WJ, Goate A, Kopan R (1999) A presenilin-1-dependent gamma-secretase-like protease mediates release of Notch intracellular domain. Nature 398:518-522.

Dewji NN, Singer SJ (1997) Cell surface expression of the Alzheimer disease-related presenilin proteins. Proc Natl Acad Sci USA 94:9926-9931.

Duff K, Eckman C, Zehr C, Yu X, Prada C-M, Perez-tur J, Hutton M, Buee L, Harigaya Y, Yager D, Morgans D, Gordons MN, Holcomb L, Refolo L, Zenk B, Hardy J, Younkin S (1996) Increased amyloidb42(43) in brains of mice expressing mutant presenilin 1. Nature 383:710-713.

Fehon RG, Kooh PJ, Rebay I, Regan CL, Xu T, Muskavitch MAT, Artavanis-Tsakonas S (1990) Molecular interactions between the protein products of the neurogenic loci Notch and Delta, two EGFhomologous genes in Drosophila. Cell 61:523-534.

Fehon RG, Johansen K, Rebay I, Artavanis-Tsakonas S (1991) Complex cellular and subcellular regulation of Notch expression during embryonic and imaginal development of Drosophila: implications for Notch function. J Cell Biol 113:657-669.

Hong C-S, Koo EH (1997) Isolation and characterization of Drosophila presenilin homolog. NeuroReport 8:665-668.

Kidd S, Baylies MK, Gasic GP, Young MW (1989) Structure and distribution of the Notch protein in developing Drosophila. Genes Dev 3:1113-1129.

Kooh PJ, Fehon RG, Muskavitch MAT (1993) Implications of dynamic patterns of Delta and Notch expression for cellular interactions during Drosophila development. Development 117:493-507.

Kovacks DM, Fausett HJ, Page KJ, Kim T-W, Moir RD, Merriam DE, Hollister RD, Hallmark OG, Mancini R, Felsenstein KM, Hyman BT, Tanzi RE, Wasco W (1996) Alzheimer-associated presenilins 1 and 2: neuronal expression in brain and localization to intracellular membranes in mammalian cells. Nat Med 2:224-229.

Levitan D, Greenwald I (1995) Facilitation of lin-12-mediated signalling by sel-12, a Caenorhabditis elegans S182 Alzheimer's disease gene. Nature 377:351-354.

Levitan D, Greenwald I (1998) Effects of SEL-12 presenilin on LIN-12 localization and function in Caenorhabditis elegans. Development 125:3599-3606.

Levitan D, Doyle TG, Brousseau D, Lee MK, Thinakaran G, Slunt HH, Sisodia SS, Greenwald I (1996) Assessment of normal and mutant human presenilin function in Caenorhabditis elegans. Proc Natl Acad Sci USA 93:14940-14944.

Levy-Lahad E, Wasco W, Poorkaj P, Romano DM, Oshima JM, Pettingell WH, Yu CE, Jondro PD, Schmidt SD, Wang K, Crowley AC, Fu Y-H, Guenette SY, Galas P, Nemens E, Wijsman EM, Bird TD, Schellenberg GD, Tanzi RE (1995) Candidate gene for the chromosome 1 familial Alzheimer's disease locus. Science 269:973-977.

Logeat F, Bessia C, Brou C, LeBail O, Jarriault S, Seidah NG, Israel A (1998) The Notch1 receptor is cleaved constitutively by a furin-like convertase. Proc Natl Acad Sci USA 95:8108-8112.

Mercken M, Takahashi H, Honda T, Sato K, Murayama M, Nakazato Y, Notuchi K, Imahori K, Takashima A (1996) Characterization of human presenilin 1 using N-terminal specific monoclonal antibodies: evidence that Alzheimer mutations affect proteolytic processing. FEBS Lett 389:297-303.

Pan D, Rubin GM (1997) Kuzbanian controls proteolytic processing of Notch and mediates lateral inhibition during Drosophila and vertebrate neurogenesis. Cell 90:271-280.

Pirrotta V (1986) Cloning Drosophila genes. In: Drosophila: a practical approach (Roberts DB, ed), pp 83-110. Oxford: IRL.
Podlisny MB, Citron M, Amarante P, Sherrington R, Xia W, Zhang J, Diehl T, Levesque G, Fraser P, Haass C, Koo EHM, Seubert P, St George-Hyslop P, Teplow DB, Selkoe DJ (1997) Presenilin proteins undergo heterogenous endoproteolysis between Thr291 and Ala299 and occur as stable $\mathrm{N}$-and $\mathrm{C}$-terminal fragments in normal and Alzheimer brain tissue. Neurobiol Dis 3:325-337.

Robinow S, White K (1988) The locus elav of Drosophila melanogaster is expressed in neurons at all developmental stages. Dev Biol 126:294-303

Robinow S, White K (1991) Characterization and spatial distribution of the elav protein during Drosophila melanogaster development. J Neurobiol 22:443-461.

Rogaev EI, Sherrington R, Rogaeva EA, Levesque G, Ikeda M, Liang Y, Chi H, Lin C, Holman K, Tsuda T, Mar L, Sorbi S, Nacmias B, Piacentini S, Amaducci L, Chumakov I, Cohen D, Lannfelt L, Fraser PE, Rommens JM, St George-Hyslop PH (1995) Familial Alzheimer's disease in kindreds with missense mutations in a gene on chromosome 1 related to the Alzheimer's disease type 3 gene. Nature 376:775-778.

Scheuner D, Eckman C, Jensen M, Song X, Citron M, Suzuki N, Bird TD, Hardy J, Hutton M, Kukull W, Larson E, Levy-Lahad E, Viitanen M, Peskind E, Poorkaj P, Schellenberg G, Tanzi R, Wasco W, Lannfelt L, Selkoe D, Younkin S (1996) Secreted amyloid $\beta$-protein similar to that in the senile plaques of Alzheimer's disease is increased in vivo by the presenilin 1 and 2 and $A P P$ mutations linked to familial Alzheimer's disease. Nat Med 2:864-865.

Schroeter EH, Kisslinger JA, Kopan R (1998) Notch1 signaling requires ligand-induced proteolytic release of the intracellular domain. Nature 393:382-386.

Seugnet L, Simpson P, Haenlin M (1997) Requirement for dynamin during notch signaling in Drosophila neurogenesis. Dev Biol 192:585-598.

Shen J, Bronson T, Chen DF, Xia W, Selkoe DJ, Tonegawa S (1997) Skeletal and CNS defects in presenilin-1 deficient mice. Cell 89:629-639.

Sherrington R, Rogaev EI, Liang Y, Rogaeva EA, Levesque G, Ikeda M, Chi H, Lin C, Li G, Holman K, Tsuda T, Mar L, Foncin J-F, Bruni AC, Montesi MP, Sorbi S, Rainero I, Pinessi L, Nee L, Chumakov I, Pollen D, Brookes A, Sanseau P, Polinsky RJ, Wasco W, Da Silva HAR, Haines JL, Pericak-Vance MA, Tanzi RE, Roses AD, Fraser PE, Rommens JM, St George-Hyslop PH (1995) Cloning of a gene bearing missense mutations in early-onset familial Alzheimer's disease. Nature 375:754-760.

Spradling AC, Rubin GM (1982) Transposition of cloned P elements into Drosophila germ line chromosomes. Science 218:341-347.

Steiner H, Capell A, Pesold B, Citron M, Kloetzel PM, Selkoe DJ, Romig H, Mendla K, Haass C (1998) Expression of Alzheimer's disease-associated Presenilin-1 is controlled by proteolytic degradation and complex formation. J Biol Chem 273:32322-32331.

Struhl G, Adachi A (1998) Nuclear access and action of Notch in vivo. Cell 93:649-660.

Struhl G, Greenwald I (1999) Presenilin is required for activity and nuclear access of Notch in Drosophila. Nature 398:522-525.

Walter J, Capell A, Grunberg J, Pesold B, Schindzielorz A, Prior R, Podlisny MB, Fraser P, St George Hyslop P, Selkoe DJ, Haass C (1996) The Alzheimer's disease-associated presenilins are differentially phosphorylated proteins located predominantly within the endoplasmic reticulum. Mol Med 2:673-691.

Walter J, Grunberg J, Capell A, Pesold B, Schindzielorz A, Citron M, Mendla K, George-Hyslop P, Multhaup G, Selkoe DJ, Haass C (1997) Proteolytic processing of the Alzheimer disease-associated presenilin-1 generates an in vivo substrate for protein kinase C. Proc Natl Acad Sci USA 94:5349-5354.

Wolfe MS, Xia W, Ostaszewski BL, Diehl TS, Kimberly WT, Selkoe DJ (1999) Two transmembrane aspartates in presenilin-1 required for presenilin endoproteolysis and gamma-secretase activity. Nature 398:513-517.

Wong PC, Zheng H, Chen H, Becher MW, Sirinathsinghji DJS, Trumbauer ME, Chen HY, Price DL, Van der Ploeg LHT, Sisodia SS (1997) Presenilin 1 is required for Notch 1 and DII1 expression in the paraxial mesoderm. Nature 387:288-291.

Ye Y, Fortini ME (1998) Characterization of Drosophila Presenilin and its colocalization with Notch during development. Mech Dev 79:199-211.

Ye Y, Lukinova N, Fortini M (1999) Neurogenic phenotypes and altered Notch processing in Drosophila Presenilin mutants. Nature 398:525529 . 